\title{
Erratum: Measuring Housework in Time Use Surveys
}

\section{W. KEITH BRYANT}

Cornell University, New York

HYOJIN KANG

Korea

CATHLEEN D. ZICK

University of Utah, Utah

ANNA CHAN

U.S. Bureau of the Census, USA

The variance for $A_{\mathrm{RE}}^{\mathrm{s}}$ reported in footnote 8 on page 45 of Bryant, Kang, Zick and Chan (2004) is in error. The correct formula is:

$$
\operatorname{Var}\left(A_{\mathrm{RE}}^{\mathrm{s}}\right)=\Sigma_{j} \bar{Z}_{s j}^{2} \sigma_{r j}^{2}+\Sigma_{j} \bar{Z}_{s j}^{2} \sigma_{d j}^{2}+2 \Sigma \Sigma_{j \neq p} \bar{Z}_{s j} \bar{Z}_{s p} \sigma_{s j p}+2 \Sigma \Sigma_{j \neq p} \bar{Z}_{s j} \bar{Z}_{s p} \sigma_{d j p}
$$

We are indebted to a discussion with Jorge Gonzalez-Chapela for discovering this error. The conclusions of the paper are not affected.

\section{Reference}

Bryant, W. Keith, Hyojin Kang, Cathleen D. Zick and Anna Chan. (2004). "Measuring Housework in Time Use Surveys." Review of Economics of the Household 2, 23-47. 